\title{
Effect of Electron-Beam Radiation and Other Sterilization Techniques on Structural, Mechanical and Microbiological Properties of Thermoplastic Starch Blend
}

\author{
Anna Iuliano ${ }^{1,2}\left(\right.$ D Agata Fabiszewska $^{1} \cdot$ Katarzyna Kozik $^{1} \cdot$ Magdalena Rzepna $^{3} \cdot$ Justyna Ostrowska ${ }^{4} \cdot$ \\ Maciej Dębowski ${ }^{2} \cdot$ Andrzej Plichta $^{2}$
}

Accepted: 11 November 2020 / Published online: 21 November 2020

(c) The Author(s) 2020

\begin{abstract}
This work investigates the potential application of various sterilization methods for microorganism inactivation on the thermoplastic starch blend surface. The influence of the e-beam and UV radiation, ethanol, isopropanol and microwave autoclave on structural and packaging properties were studied. All the applied methods were successful in the inactivation of yeast and molds, however only the e-beam radiation was able to remove the bacterial microflora. The FTIR analysis revealed no significant changes in the polymer structure, nevertheless, a deterioration of the mechanical properties of the blend was observed. The least invasive method was the UV radiation which did not affect the mechanical parameters and additionally improved the barrier properties of the tested material. Moreover, it was proved that during the e-beam radiation the chain scission and cross-linking occurred. The non-irradiated and irradiated samples were subjected to the enzymatic degradation studies performed in the presence of amylase. The results indicated that irradiation accelerated the decomposition of material, which was confirmed by the measurements of weight loss, and mass of glucose and starch released to the solution in the course of biodegradation, as well as the FTIR and thermal analysis.
\end{abstract}

Keywords Electron-beam radiation $\cdot \operatorname{Starch} \cdot$ B. subtilis $\cdot$ Degradation $\cdot$ Mechanical properties

\section{Introduction}

Electronic supplementary material The online version of this article (https://doi.org/10.1007/s10924-020-01972-9) contains supplementary material, which is available to authorized users.

Anna Iuliano

aiuliano@ch.pw.edu.pl

1 Department of Chemistry, Institute of Food Sciences, Warsaw University of Life Sciences - SGGW,

Nowoursynowska 159c, 02-776 Warsaw, Poland

2 Faculty of Chemistry, Warsaw University of Technology, Noakowskiego 3, 00-664 Warsaw, Poland

3 Institute of Nuclear Chemistry and Technology, Dorodna 16, 03-195 Warsaw, Poland

4 Department of Organic Technologies, The Łukasiewicz Research Network - New Chemical Syntheses Institute, al. Tysiąclecia Państwa Polskiego 13A, 24-110 Puławy, Poland
Sterilization is a process, which allows for a complete destruction or removal of all microorganisms that could contaminate packaging materials and thereby constitute a health hazard [1]. The choice of a proper sterilization technique depends on the material used. There is no universal method for polymer sterilization. Every potential material has to go through a detailed analysis of its susceptibility to sterilization and all the packaging properties have to be investigated. Some of the polymers (both natural and synthetic) treated with superheated steam, hot air or high temperature undergo deformation, thermal and oxidative degradation and in many cases hydrolysis if they are susceptible. In those circumstances better results might be provided by other methods such as: ethylene oxide [2], hydrogen peroxide [3], ethyl alcohol [4], gamma [5] and electron-beam (e-beam) radiation [6], plasma [7]. Moreover, the process of choosing the right method is even more complicated, if we look for the sterilization technique dedicated for food packaging. In that case, the analysis concerns the sterilization effect 
on microbiological interactions, packaging properties and changing biomolecules in food [8].

The most commonly used biodegradable material in the food packaging industry is thermoplastic starch, TPS [9]. TPS can be obtained in the course of destruction of the crystalline phase of the native starch by thermal and mechanical methods using a plasticizer, such as water, glycerol, urea or sorbitol, which reduces the glass transition temperature and melting point of starch [10]. After the modification, starch can be processed by standard methods used for thermoplastic polymers such as extrusion, injection molding, thermoforming and hotpressing [11]. However, high hydrophilicity, low degradation temperatures and poor mechanical properties of TPS give a limitation for its various industrial applications [12]. The solution to this problem can be blending of starch with more hydrophobic biodegradable polyesters. The most studied starch blends are those based on poly(butylene adipate-co-terephthalate), PBAT [13, 14], poly( $\varepsilon$-caprolactone), PCL [15, 16], polylactide, PLA [11] and poly(butylene succinate), PBS [17, 18]. In all cases, the introduction of TPS into polyester matrix caused significant reduction in mechanical properties and several attempts were made in order to improve the miscibility with biodegradable polyesters. For this purpose poly(ethyleneco-vinyl alcohol), maleic anhydride [13] as well as PCL [19], PLA [20], PBAT [21], grafted with maleic anhydride and/or glycidyl methacrylate were used. However, it was also proved that mechanical properties and morphology of the PBAT/TPS blend can be controlled solely by changing the compounding parameters [14].

In the presented paper the influence of various sterilization techniques on the structure and packaging properties of the TPS/PBS blend (50/50 wt $\%$ ) plasticized with $5 \mathrm{wt} \%$ of glycerol and $25 \mathrm{wt} \%$ of urea were examined. PBS is a biodegradable polymer with good mechanical and thermal properties, good processability and high chemical resistance. Moreover, it can be obtained from the renewable resources. In the literature, numerous studies regarding blending of TPS with PBS can be found, however so far, none of them reported the susceptibility of such a blend to sterilization. For our studies we selected some standard sterilization techniques such as: the e-beam and UV radiation, a treatment with a isopropanol and ethanol as well as microwave autoclave and we evaluated their sterilization efficiency. Due to the fact, that some of those techniques can change the material properties and its structural characteristic, the susceptibility to degradation as well as thermal, mechanical, morphological, and barrier properties were also investigated.

\section{Materials and Methods}

\section{Materials}

$\alpha$-Amylase from Aspergillus oryzae (powder, $~ 30 \mathrm{U}$ $\mathrm{mg}^{-1}$ ), sodium azide (>99.5\%), trichloroacetic acid (TCA, 99\%), dinitrosalicylic acid (DNS, 98\%) were obtained from Sigma-Aldrich (USA). All medium ingredients (agar-agar, yeast extract, peptone, Sabouraud chloramphenicol agar) were purchased from BTL (Poland). Soluble starch (pure p.a.), glucose (pure p.a.), citric acid monohydrate $(99.5 \%)$, inorganic salts $\left[\mathrm{NH}_{4} \mathrm{NO}_{3}\right.$ (pure p.a.), $\left(\mathrm{NH}_{4}\right)_{2} \mathrm{SO}_{4}$ (pure p.a.), $\mathrm{K}_{2} \mathrm{HPO}_{4}$ (pure p.a.), $\mathrm{KH}_{2} \mathrm{PO}_{4}$ (pure p.a.), $\mathrm{NaCl}$ (pure p.a.)], isopropanol ( $\mathrm{PrOH}, 99.5 \%)$ and ethanol (EtOH, 96\%) were obtained from POCH (Poland). All reagents were applied without further purification. The PBS homopolymer (Bionolle 1001MD) was supplied by Showa Denko (Japan). Native potato starch was purchased from "TRZEMESZNO" Sp. z o.o. Potato Industry Company (Poland). Urea was obtained from Grupa Azoty Zakłady Azotowe "Puławy" (Poland) and glycerol (99.5\%) purchased from Brenntag (Poland).

\section{Preparation of the TPS/PBS Blend}

The film sample made of the PBS/TPS (50/50 wt\%) blend was prepared by the blown film method using a single screw extruder (Labtech Engineering, Thailand, L/D $=30$, $\mathrm{D}=20 \mathrm{~mm}$ ). The temperatures ranging from 130 to $140{ }^{\circ} \mathrm{C}$ were applied and the die temperature was set at $140{ }^{\circ} \mathrm{C}$. Starch was plasticized by urea and glycerol ( $25 \mathrm{wt} \%$ and $5 \mathrm{wt} \%$, respectively). The neat PBS sample was prepared by the same method, but at the different temperature-the extruder was operated at $135-150{ }^{\circ} \mathrm{C}$. The PBS film was characterized by $\mathrm{M}_{\mathrm{w}}=78.9 \mathrm{~kg} \mathrm{~mol}^{-1}$ and $\bigoplus_{\mathrm{M}}=7.9$.

\section{Sterilization Techniques}

\section{Irradiation}

The TPS/PBS film was irradiated on the one side of the polymer foil in an air atmosphere at ambient temperature with doses of 5, 13 and $26 \mathrm{kGy}$ using $10 \mathrm{MeV}$ electron beam generated in the linear electron accelerator Elektronika $10 / 10$. The UV irradiation $(\lambda=254 \mathrm{~nm})$ was performed using a $6 \mathrm{~W}$ lamp. Each sample was irradiated for $20 \mathrm{~min}$ (10 min per each side). 


\section{Thermal Sterilization in Microwave Autoclave}

The polymer foil placed in the $500 \mathrm{~mL}$ flask filled with $200 \mathrm{~mL}$ of distillated water and sterilized using a MicroJet microwave autoclave (Enbio, Poland) at temperature of $121{ }^{\circ} \mathrm{C}$ for $20 \mathrm{~min}$. After the sterilization process, water from the flask was aseptically removed.

\section{Alcohol Sterilization}

Each sample was incubated in a diluted ethanol (70\%) or isopropanol for $30 \mathrm{~min}$ and washed with a sterile distilled water.

\section{Gas Chromatography}

A Shimadzu gas chromatograph type GC 2014 equipped with a thermal conductivity detector and column packed with molecular sieves 5A, was applied for analyses of the gaseous products formed in samples submitted for the electron irradiation (hydrogen analysis), as well as for the calculation of the loss of oxygen from the atmosphere surrounding the sample in the irradiation vessel. The chromatographic system was working at $100{ }^{\circ} \mathrm{C}$, whereas the column and detector were kept at $120^{\circ} \mathrm{C}$. The rate of the carrier gas flow was $10 \mathrm{~mL} \mathrm{~min}^{-1}$.

\section{Structural and Thermal Properties}

The FTIR spectra were recorded on a Nicolet iS5 ATR Thermo Scientific spectrometer equipped with a diamond crystal iD7 ATR sampling component. The molar mass and polydispersity $\left(\bigoplus_{M}\right)$ were determined by gel permeation chromatography (GPC) on a Viscotek system comprising GPCmax and TDA 305 triple detection unit (RI, IV, LS) equipped with one guard and two DVB Jordi gel columns (102-107, linear, mix bed) in $\mathrm{CH}_{2} \mathrm{Cl}_{2}$ as eluent at $35^{\circ} \mathrm{C}$ at a flow rate of $1.0 \mathrm{~mL} \mathrm{~min}{ }^{-1}$. The results were analyzed by OMNIC 9.0 software. DSC analysis was carried out with a TA Instrument Model Q20 calorimeter under nitrogen flow. The sample was heated from 20 to $150{ }^{\circ} \mathrm{C}$ at a heating rate of $10^{\circ} \mathrm{C} \mathrm{min}^{-1}$ and cooled from 150 to $-90{ }^{\circ} \mathrm{C}$ at the same heating rate. Next, a second heating scan was performed from -90 to $150{ }^{\circ} \mathrm{C}$ at a heating rate of $20{ }^{\circ} \mathrm{C} \min ^{-1}$ to determine $\mathrm{T}_{\mathrm{g}}$ temperature. The thermal stability between 30 and $600{ }^{\circ} \mathrm{C}$ was investigated using a TA Instrument TGA Q500 instrument under a steady flow of nitrogen $(60 \mathrm{~mL}$ $\mathrm{min}^{-1}$ ) at a heating rate of $10^{\circ} \mathrm{C} \mathrm{min}^{-1}$.

\section{Scanning Electron Microscopy}

Scanning electron microscopy (SEM) images were obtained on a Zeiss Ultra Plus apparatus working at a voltage of $2 \mathrm{kV}$. Before the measurements the polymer film was covered with an electron-conductive carbon layer utilizing a high-vacuum sputter coater.

\section{Mechanical and Barrier Properties}

The tensile properties were examined with an Instron mechanical tester, model 5566, at tensile speed of $10 \mathrm{~mm}$ $\mathrm{min}^{-1}$ at room temperature with head of maximum load of 100 N. The Young's modulus, tensile strength and elongation at break were measured. The measurements were repeated from four to five times, for each material. Barrier properties were determined based on the water vapor permeability (WVP) according to Nowacka et al. [22]. The barrier measurement was repeated three times for each material.

\section{Analysis of Microorganisms Inactivation by Different Sterilization Techniques}

The TPS/PBS foil with dimension of $3 \times 3 \mathrm{~cm}$ was sterilized by a selected sterilization technique and then incubated for 14 days in culture media, such as: nutrient agar prepared according to PN-EN ISO 4833:2004 [for determination of the total number of bacteria (OLB)]; medium for determining the total number of yeasts (YPG) and medium for a mold growth (PL) prepared according to PN-ISO 7954:1999. The flask cultures were put on a IKA KS 4000 ic control rotaryshaker at $140 \mathrm{rpm}$, at $20{ }^{\circ} \mathrm{C}$ for the mold cultivation or at $28^{\circ} \mathrm{C}$ for the yeast and bacteria growth. The optical density of media incubated with TPS/PBS polymer film was measured each day at a wavelength of $600 \mathrm{~nm}$ to estimate the growth of microorganisms which survived the sterilization process. The medium was considered as infected when the $\mathrm{OD}_{600}$ value exceeded 0.7 what corresponded to the number of microorganism cells of 6.0-7.0 log cfu $\mathrm{mL}^{-1}$. In that case the flask culture was being disturbed and the culture broth was used for identification of the species that originated from sterilized polymer films. The liquid culture media contained: $2.5 \mathrm{~g} \mathrm{~L}^{-1}$ yeast extract, $5 \mathrm{~g} \mathrm{~L}^{-1}$ peptone, $10 \mathrm{~g}$ $\mathrm{L}^{-1}$ glucose for the OLB medium; $10 \mathrm{~g} \mathrm{~L}^{-1}$ yeast extract, $20 \mathrm{~g} \mathrm{~L}^{-1}$ peptone, $20 \mathrm{~g} \mathrm{~L}^{-1}$ glucose for the YPG medium and $1 \mathrm{~g} \mathrm{~L}^{-1} \mathrm{NH}_{4} \mathrm{NO}_{3}, 1 \mathrm{~g} \mathrm{~L}^{-1}\left(\mathrm{NH}_{4}\right)_{2} \mathrm{SO}_{4}, 4 \mathrm{~g} \mathrm{~L}^{-1} \mathrm{~K}_{2} \mathrm{HPO}_{4}$, $2 \mathrm{~g} \mathrm{~L}^{-1} \mathrm{KH}_{2} \mathrm{PO}_{4}, 1 \mathrm{~g} \mathrm{~L}^{-1} \mathrm{NaCl}, 10 \mathrm{~g} \mathrm{~L}^{-1}$ glucose, $1 \mathrm{~g} \mathrm{~L}^{-1}$ yeast extract, $57 \mathrm{~mL} \mathrm{~L}^{-1}$ citric acid for the PL medium. To prepare solid medium, $20 \mathrm{~g} \mathrm{~L}^{-1}$ of agar was additionally added. The concentration of Sabouraud chloramphenicol agar was $44.5 \mathrm{~g} \mathrm{~L}^{-1}$.

\section{Isolation and Identification of Microorganism from Polymer Films}

The second stage of the experiment concerned the isolation of microorganisms existing on the films after sterilization, which were grown in flask cultures during a 14-day of 
incubation in culture media. From each infected flask $1 \mathrm{~mL}$ of culture broth was inoculated onto agar plates ( $2 \%$ of agar medium in relation to the amount of medium used in a flask culture experiment). In parallel, for OLB culture broth an additional inoculation was performed on Sabouraud agar medium containing chloramphenicol. In such samples the bacterial growth was inhibited, which allowed to determine whether yeast or molds were present in the supernatant. The inoculated plates were incubated for three days at $20{ }^{\circ} \mathrm{C}$ or $28^{\circ} \mathrm{C}$. Individual colonies were isolated, kept on agar slants at $4{ }^{\circ} \mathrm{C}$ and subjected to species identification.

To identify isolated microorganisms, selected regions of the 16S and 26S rRNA genes were amplified by PCR (polymerase chain reaction) (Applied Biosystems Thermal Cycler) using primers of the highly conserved regions found within these sequences: $27 \mathrm{~F}$ (5'-AGA GTT TGA TCM TGG CTC AG-3') and 1492R (5'-CGG TTA CCT TGT TAC GAC TT- $3^{\prime}$ ) for bacteria and NL1 (5'-TGC TGG AGC CAT GGA TC-3') and NL4 (5'-GGT CCG TGT TTC AAG ACG G-3') for fungi. The PCR product was sequenced by the Sanger method and the results were assembled in the Geneious software. The obtained DNA sequences were compared with the $16 \mathrm{~S}$ and 26S rRNA sequences in the NCBI GenBank database, which allowed to identify the cultured microorganisms.

\section{Cultivation of B. subtilis and the Enzyme Activity Measurements}

A wild strain of Bacillus subtilis with a high amylase activity was selected from the microflora of organisms inhabiting the TPS/PBS films. Enzymes produced by the bacterial strain were used to degrade the TPS/PBS film.

Bacillus subtilis for the synthesis of amylolytic enzymes was cultured in a medium of $\mathrm{pH} 7.5$ containing $5 \mathrm{~g} \mathrm{~L}^{-1}$ yeast extract, $10 \mathrm{~g} \mathrm{~L}^{-1}$ peptone, $20 \mathrm{~g} \mathrm{~L}^{-1}$ starch, $10 \mathrm{~g} \mathrm{~L}^{-1}$ $\mathrm{NaCl}$ in $500 \mathrm{~mL}$ flasks on a rotary shaker at $37^{\circ} \mathrm{C}$. The $24 \mathrm{~h}$ culture of the bacterial cells in the OLB medium was used as an inoculum in a volume of $2 \mathrm{~mL}$. The flasks were removed every $24 \mathrm{~h}$ and $1 \mathrm{~mL}$ of the culture supernatant was centrifuged for $10 \mathrm{~min}$ at $10,000 \mathrm{rpm}$ for amylolytic enzyme assay. The measurement of amylase activity was performed according to a modified method described in the literature [23]. $50 \mu \mathrm{L}$ of starch solution $\left(0.01 \mathrm{~g} \mathrm{~mL}^{-1}\right.$ in phosphate buffer of $\mathrm{pH} 6.4$ ) and $50 \mu \mathrm{L}$ of clear supernatant was added to the glass vials. The blank sample, without supernatant, was also prepared. The reaction was carried out for $30 \mathrm{~min}$ at $50{ }^{\circ} \mathrm{C}$ and stopped by adding $50 \mu \mathrm{L}$ of TCA. Additionally, $50 \mu \mathrm{L}$ of supernatant added to the blank sample for volume equalization. Immediately before the absorbance measurement $5 \mathrm{~mL}$ redistilled water and 150 $\mu \mathrm{L}$ of iodine were added. The absorbance of the solution was determined at a wavelength of $580 \mathrm{~nm}$. One unit (U) of enzyme activity for the starch-iodine assay was defined as the disappearance of an average of $1 \mathrm{mg}$ of iodine binding starch $\mathrm{min}^{-1}$ in the analyzed reaction. The $\mathrm{U} \mathrm{mL}^{-1}$ value was calculated using the formula: $\mathrm{U} \mathrm{mL}^{-1}=\left(A_{580 \mathrm{blank}}\right.$ $\left.-A_{580 \text { sample }}\right) / A_{580 / \mathrm{mg} \mathrm{starch}} 30 \mathrm{~min}^{-1} 0.05 \mathrm{~mL}^{-1}$, where $A_{580 \mathrm{blank}}$ is the absorbance obtained from the starch without the addition of enzyme, $A_{580 \text { sample }}$ is the absorbance for the starch digested with enzyme, $A_{580 / \mathrm{mg} \text { starch }}$ is the absorbance for $1 \mathrm{mg}$ of starch as derived from the standard curve, $30 \mathrm{~min}$ is the assay incubation time, and $0.05 \mathrm{~mL}$ is the volume of the enzyme used in the assay.

\section{Degradation in the Presence of Commercial Enzymes and Enzyme of Microbial Origin}

The TPS/PBS film were cut into $2.0 \times 2.0 \mathrm{~cm}$ strips with thickness $0.2 \mathrm{~mm}$. Each film was placed in a separate Erlenmeyer flask containing $10 \mathrm{~mL}$ of acetate buffer (pH 5.5), $6 \mathrm{mg}$ of amylase and $60 \mathrm{mg}$ of sodium azide. In case of degradation in the presence of enzyme from $B$. subtilis, $10 \mathrm{~mL}$ of post-culture liquid was placed in an Erlenmeyer flask and $60 \mathrm{mg}$ of sodium azide was added. The film-enzyme incubations were carried out at $37^{\circ} \mathrm{C}$ in a rotary shaker $(150 \mathrm{rpm})$. At the specific time points, respective films were removed from the shaker incubator, rinsed thoroughly with distilled water, and then dried under reduced pressure $(0.5 \mathrm{mbar})$ at room temperature for $48 \mathrm{~h}$. The experimental weight loss values represent the averages of weight measurements carried out for the three replicate films. The starch and reducing sugars concentration in the solution resulting from a degradation experiment was determined according to the procedures previously described [24].

\section{Degradation in the Presence of Wild B. subtilis Strain in the Solid Agar Medium}

Mineral medium, prepared according to the procedure described in the ASTM G21-96(2002) standard, was aseptically poured into Petri plates. TPS/PBS film was cut into $2 \times 2 \mathrm{~cm}$ strips, irradiated with a dose of $5 \mathrm{kGy}$ and sterilely placed in the center of Petri plates containing the mineral medium deprived of any carbon source. The inoculum of $0.2 \mathrm{~mL}$ was transferred on each sample and smoothly spread using a cell spreader. The petri plates were incubated at 37 ${ }^{\circ} \mathrm{C}$. After 1, 2 and 3 weeks, respective films were removed, washed with ethyl alcohol, and then dried under a reduced pressure $(0.5 \mathrm{mbar})$ at room temperature for $48 \mathrm{~h}$. The experimental weight loss values represent the averages of weight measurements carried out for the three replicate films. The inoculum from $B$. subtilis was prepared using the OLB medium and the initial spore concentration was $1.81 \times 10^{8}$ cfu $\mathrm{mL}^{-1}$. 


\section{Results and Discussion}

\section{Microbiological Purity Test}

In order to determine the microorganism inactivation ability of the selected sterilization techniques, the TPS/ PBS polymer film was sterilized with each technique and aseptically placed in the bacterial, yeast and mold culture media. The incubation was stopped when the microbial growth was observed and the optical density at $600 \mathrm{~nm}$ exceeded 0.6. The obtained results are summarized in Table 1. A $30 \mathrm{~min}$ incubation time in alcohols was chosen based on the preliminary experiments, which showed that the OLB medium was infected already after $24 \mathrm{~h}$ for the sample incubated for $1 \mathrm{~min}$ and $10 \mathrm{~min}$ in isopropanol. For this reason we extended the exposure time to $30 \mathrm{~min}$.

All of the applied e-beam radiation doses were effective in microorganism inactivation. The radiation dose of $26 \mathrm{kGy}$ kept the microbial population below $1 \log _{10} \mathrm{cfu}$ $\mathrm{mL}^{-1}$ after 14 days of incubation at $30^{\circ} \mathrm{C}$. The other sterilization techniques were successful in mold inactivation, however the microbial growth was observed between $24 \mathrm{~h}$ and $96 \mathrm{~h}$ in OLB and YPG medium. In those cases, the streaking was done for each cultivation in order to isolate a single colony and analyze using genetic techniques, the type of species which survived the sterilization conditions. The isolated species are presented in the last column of Table 1. As can be seen, the polymer film surface was inhabited by Bacillus genera.

In general, steam and dry heat sterilization are considered as the best sterilization techniques due to the high penetration ability and the absence of toxic residues [25]. The mechanism of sterilization is based on the destruction of replication metabolic and structural components of microorganisms and in case of dry heat also dehydration followed by oxidation [4]. However, according to the literature, Bacillus sp. spores are highly resistant to heat and other sterilization techniques. This phenomena is associated with impermeability, low water content, high levels of pyridine-2,6-dicarboxylic acid and divalent cations, and outer membrane thickness [26]. Moreover, the spore DNA is protected against various types of damage. That is why, steam sterilization, alcohol solutions [27] and the UV radiation [28] did not inactivate the $B$. subtilis spores and all those methods have to be supported by other sterilization techniques. In case of ionizing radiation, mechanism of inactivation covers structural damage, spilling of cytoplasmic contents, reduction in membrane integrity and fragmentation of genomic DNA. The e-beam radiation has the ability to inactivate both gram-negative and gram-positive bacteria, however, some endospores are resistant even to high doses of radiation [29, 30] and some additional heat treatment is required for the complete microorganism inactivation. In our previous studies [6] we proved that the e-beam radiation is effective in microorganism inactivation on a hydrophobic surface of the PBAT/PLA polyester blend. According to the current results, it seems that it is also possible to sterilize the hydrophilic surface of the TPS/PBS blend, even by using a very small dose of radiation. It can be concluded that there is not a wide range of methods allowing for a complete microorganisms inactivation. Although the e-beam radiation seemed to be the perfect method for the TPS/PBS blends sterilization, a high cost of this method inclines to further experiments on a combination of radiation and some physicochemical methods for inactivation of the microflora colonizing surfaces of those polymers. However, combined techniques of sterilization will be the subject matter of another article.

\section{FTIR Characterization of the TPS/PBS Blend Before and After Sterilization}

The structure of material before and after sterilization was analyzed based on the FTIR spectra, in which several regions characteristic for starch, PBS, urea and glycerol were observed (Fig. 1a). The $\mathrm{O}-\mathrm{H}$ and $\mathrm{C}-\mathrm{O}$ stretching vibrations of the starch give strong bands at the range of $36,003,000 \mathrm{~cm}^{-1}$ and $1022-970 \mathrm{~cm}^{-1}$, respectively. The first region $\left(3427-3255 \mathrm{~cm}^{-1}\right)$ can be also attributed to $\mathrm{N}-\mathrm{H}$ stretching bands of urea, however, the most characteristic signals for urea are located at $1678 \mathrm{~cm}^{-1}, 1594 \mathrm{~cm}^{-1}$,

Table 1 Results of sterilization method of the TPS/PBS blend

\begin{tabular}{|c|c|c|}
\hline Sterilization method & Contact time & Result of sterilization method \\
\hline Autoclave & $20 \mathrm{~min}$ & $\begin{array}{l}\text { Infected within 1-4 days; isolated species: B. altitudinis, B. aerophilus } \\
\text { B. stratosphericus, B. pumilus }\end{array}$ \\
\hline $\mathrm{PrOH}$ & $30 \mathrm{~min}$ & Infected within 3-4 days; isolated species: $B$. subtilis, $B$. gibsonii \\
\hline $\mathrm{EtOH}$ & $30 \mathrm{~min}$ & Infected after 2 days; isolated species: $B$. subtilis, $B$. gibsonii \\
\hline UV & 10 min per side & Infected within 2-3 days; isolated species: $B$. subtilis, $B$. gibsonii \\
\hline e-Beam irradiation & Direct exposure: $2-4 \mathrm{~s}$ & Effective in inactivating microorganisms $\mathrm{s}^{\mathrm{a}}$ \\
\hline
\end{tabular}

${ }^{a}$ The presented data were determined independently of the irradiation dose used 


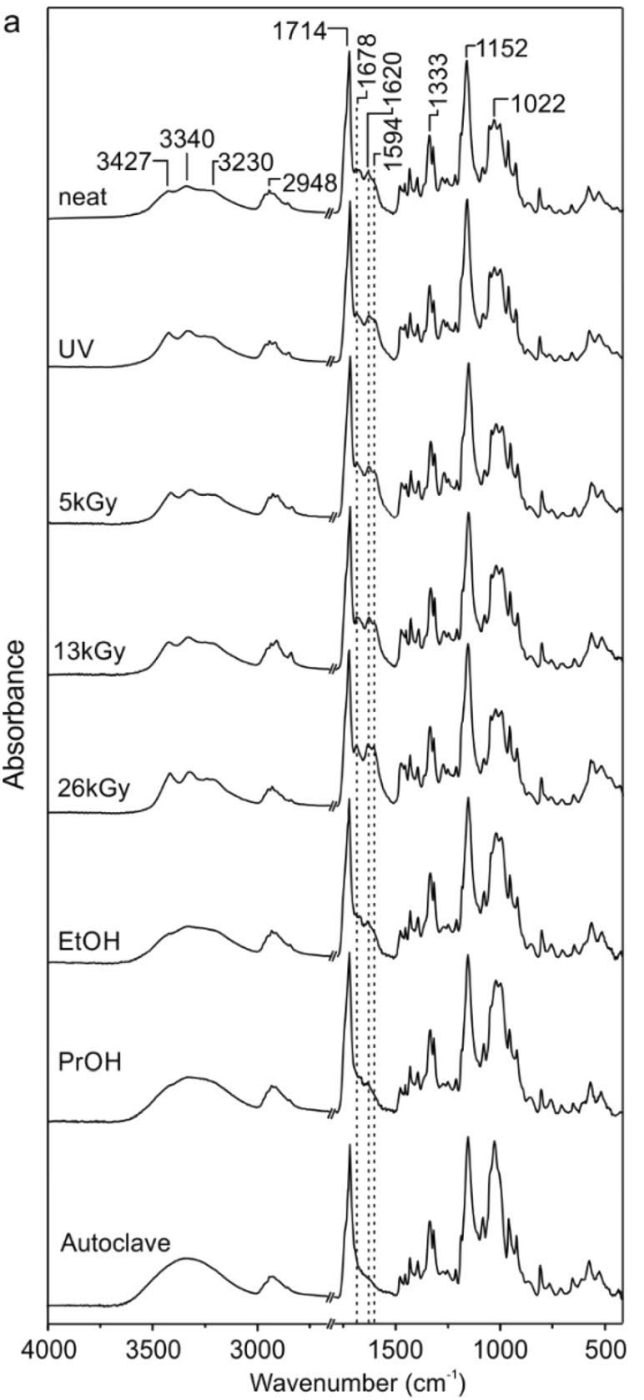

b

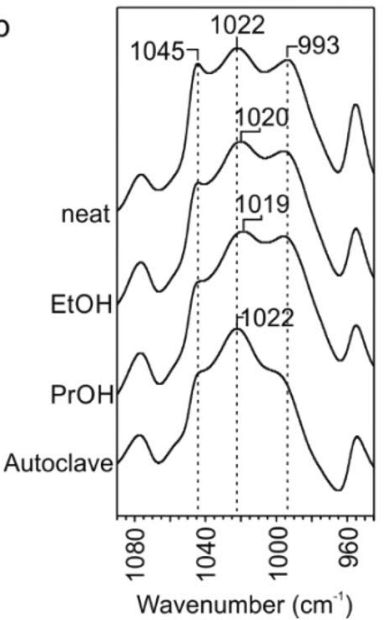

Fig. 1 a FTIR spectra of the TPS/PBS blends before and after sterilization by: UV irradiation, e-beam irradiation with the doses of $5 \mathrm{kGy}, 13 \mathrm{kGy}$, $26 \mathrm{kGy}$, ethanol, isopropanol and microwave autoclave, and b FTIR spectra (a 1085-950 $\mathrm{cm}^{-1}$ region) of the TPS/PBS blend before and after sterilization in alcohol solutions or microwave autoclave
$1460 \mathrm{~cm}^{-1}$ assigned to the $\mathrm{C}=\mathrm{O}$ stretching mode, $\mathrm{N}-\mathrm{H}$ bending band and $\mathrm{C}-\mathrm{N}$ stretching vibration, respectively [24]. The FTIR absorption band at $3000-2800 \mathrm{~cm}^{-1}$ is attributed to the $\mathrm{C}-\mathrm{H}$ stretching vibrations in both starch and PBS. In case of PBS the absorption bands located at $1714 \mathrm{~cm}^{-1}$ and $1152 \mathrm{~cm}^{-1}$ were attributed to the $\mathrm{C}=\mathrm{O}$ and $\mathrm{C}-\mathrm{O}$ stretching vibrations in the ester group, respectively [31].

The FTIR spectra of TPS/PBS blend are difficult to analyze due to a high overlap of several bands making their assignment very complicated, however, few conclusions can be drawn. According to the literature data, the UV radiation does not cause significant changes in the FTIR spectrum of starch, even after $13 \mathrm{~h}$ of exposure [32]. As can be seen in Fig. 1a, all signals in the analyzed regions, did not change the position or intensity. The same observation was conducted for the polymer films treated with the e-beam radiation. In this case, we would expect some decrease in the intensity of the bands between 3000 and $2800 \mathrm{~cm}^{-1}$, as the hydroxyl radicals formed by water radiolysis rapidly attack the $\mathrm{C}-\mathrm{H}$ bonds liberating the hydrogen atom from the bond [33]. However, due to the fact, that the radiation was performed under non-aqueous conditions such changes were negligible, even if some amount of water, used as a TPS plasticizer, was present in the blend. The sterilization by alcohols and microwave caused partial leaching of plasticizers observed as a decrease in the intensity of the band in the $1690-1550 \mathrm{~cm}^{-1}$ region. Additionally, due to the lower content of urea in the blend, one can observe the change in the intensity ratio of the starch signals located between 1022 and $993 \mathrm{~cm}^{-1}$, which indicates the weakening of hydrogen bonds between starch and plasticizers (Fig. 1b) [34].

\section{Thermal Analysis}

Differential scanning calorimetry (DSC) was used to identify the transition temperatures and enthalpy of fusion of the PBS phase as well as its degree of crystallization $\left(x_{\mathrm{c}}\right)$. All these data are collected in Table 2. As can be seen, all samples exhibited melting and crystallization. Additionally, during the 2nd heating cycle (Fig. S1 in Supplementary Material) a double melting peak was observed which is associated with the melt-recrystallization process of the high molar mass PBS. These two peaks represent two different distributions of lamellae having different thermal properties. This phenomena is well known and described in the literature [35].

The melting point $\left(\mathrm{T}_{\mathrm{m}}\right)$, glass transition $\left(\mathrm{T}_{\mathrm{g}}\right)$ and melt crystallization temperature $\left(T_{c}\right)$ of PBS were almost unaffected by the UV or e-beam radiation, although degree of crystallinity increased with increasing radiation dose. This phenomenon can be attributed to the radiation-induced chain scission process. A similar thermal properties was exhibited by samples treated with the alcohol solutions. In that case the crystallinity degree increased for about $3 \%$. 
Table 2 Thermal parameters of the TPS/PBS blend before and after sterilization determined by DSC and TG

\begin{tabular}{|c|c|c|c|c|c|c|c|c|c|c|}
\hline Sample & $\mathrm{T}_{\mathrm{g}}\left({ }^{\circ} \mathrm{C}\right)$ & $\mathrm{T}_{\mathrm{m}}\left({ }^{\circ} \mathrm{C}\right)$ & $\mathrm{T}_{\mathrm{c}}\left({ }^{\circ} \mathrm{C}\right)$ & $x_{c}(\%)$ & $\begin{array}{l}\text { Mass loss }(\%) \\
\text { up to } 230^{\circ} \mathrm{C}\end{array}$ & $\begin{array}{l}\text { Mass loss (\%) } \\
\text { up to } 450^{\circ} \mathrm{C}\end{array}$ & $\mathrm{T}_{\text {onset } 3}\left({ }^{\circ} \mathrm{C}\right)$ & $\mathrm{T}_{\text {onset } 4}\left({ }^{\circ} \mathrm{C}\right)$ & $\mathrm{T}_{\text {onset3* }}\left({ }^{\circ} \mathrm{C}\right)$ & $\mathrm{T}_{\text {onset } 4 *}\left({ }^{\circ} \mathrm{C}\right)$ \\
\hline Neat & -30.1 & 111 & 88.1 & 54.7 & 11.0 & 78.8 & 300 & 374 & - & - \\
\hline UV & -27.5 & 112 & 87.6 & 56.6 & 8.5 & 82.2 & 302 & 376 & - & - \\
\hline $5 \mathrm{kGy}$ & -29.3 & 112 & 87.6 & 58.1 & 10.5 & 79.8 & 301 & 375 & 299 & 372 \\
\hline 13 kGy & -29.8 & 111 & 87.9 & 58.4 & 10.2 & 79.5 & 302 & 375 & 298 & 372 \\
\hline $26 \mathrm{kGy}$ & -29.6 & 112 & 87.1 & 62.3 & 10.4 & 78.2 & 302 & 375 & 295 & 370 \\
\hline $\mathrm{EtOH}$ & -30.3 & 111 & 87.9 & 58.4 & - & - & - & - & - & - \\
\hline $\mathrm{PrOH}$ & -29.9 & 112 & 88.0 & 57.0 & - & - & - & - & - & - \\
\hline Autoclave & -32.9 & 110 & 78.1 & 73.8 & - & - & - & - & - & - \\
\hline
\end{tabular}

$\mathrm{T}_{\mathrm{g}}$ (glass transition) and $\mathrm{T}_{\mathrm{m}}$ (melting temperature) were determined by the $2 \mathrm{nd}$ and 1 st heating scan, respectively. $\mathrm{T}_{\mathrm{c}}$ (melt crystallization temperature) was determined by cooling scan. The crystallinity degree $\left(x_{c}\right)$ was calculated according to equation $x_{\mathrm{c}}=\Delta \mathrm{H}_{m} /\left(\Delta \mathrm{H}_{m}^{o} \cdot \omega\right) \cdot 100$, where $\Delta \mathrm{H}_{m}^{o}$ $=110.5 \mathrm{~J} \mathrm{~g} \mathrm{~g}^{-131}$ and $\omega$ is a weight percentage of PBS in the blend. $\mathrm{T}_{\text {onset } 3}$ and $\mathrm{T}_{\text {onset } 4}$ relate to the degradation of TPS and PBS in the polymer blend, respectively. The $\mathrm{T}_{\text {onset }}$ values of the respective degradation steps estimated for the irradiated samples stored for 26 months are indicated with *

Fig. 2 Radiation yield of a hydrogen $\left(\mathrm{GH}_{2}\right)$ and $\mathbf{b}$ oxygen $\left(\mathrm{GO}_{2}\right)$ in the function of radiation dose
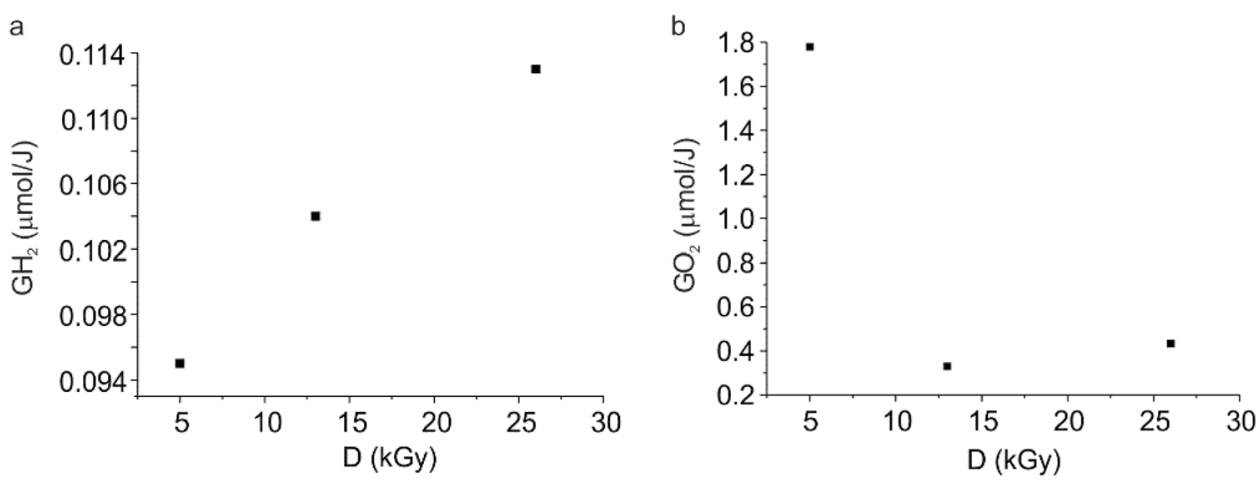

The TPS/PBS blend after sterilization in the autoclave was characterized by slightly lower $\mathrm{T}_{\mathrm{m}}$ and melt crystallization temperature reduced by ca. $10{ }^{\circ} \mathrm{C}$. The reduction in the $\mathrm{T}_{\mathrm{c}}$ can be associated with the degradation process as well as to the presence of water interacting with the starch molecules after sterilization and it correlated well with the drop in the $\mathrm{T}_{\mathrm{g}}$ value.

In general, during the e-beam irradiation two processes occur: cross-linking and chain scission. Depending on the polymer blend composition, one of those processes can dominate in the system. From the DSC results, it seems that the TPS/PBS blend underwent slow degradation and the creation of the cross-linked structures was limited. The occurrence of the radiation-related cross-linking processes has been confirmed by a gas chromatography on the basis of the hydrogen radiation yield $\left(\mathrm{GH}_{2}\right)$ (Fig. 2a), which is proportional to the number of free radicals [36]. For the analyzed samples, $\mathrm{GH}_{2}$ was equal to $0.10 \mu \mathrm{mol} \mathrm{J}^{-1}$. Interestingly, the calculated yield is more than twice lower than in the case of potato starch $\left(\mathrm{GH}_{2}=0.26 \mu \mathrm{mol} \mathrm{J}{ }^{-1}\right)$ and similar to the blend of thermoplastic starch with an aliphatic-aromatic polyester, which exhibit a protective effect against the radiolysis. The
Table 3 Molar mass and polydispersity of the PBS fraction in the TPS/PBS blend before and after irradiation

\begin{tabular}{llll}
\hline Sample & $\mathrm{M}_{\mathrm{n}}{ }^{\mathrm{a}}\left(\mathrm{kg} \mathrm{mol}^{-1}\right)$ & $\mathrm{M}_{\mathrm{w}}{ }^{\mathrm{a}}\left(\mathrm{kg} \mathrm{mol}^{-1}\right)$ & $\mathrm{Ð}_{\mathrm{M}}{ }^{\mathrm{a}, \mathrm{b}}$ \\
\hline $0 \mathrm{kGy}$ & 11.0 & 69.5 & 6.32 \\
$5 \mathrm{kGy}$ & 10.3 & 70.8 & 6.86 \\
$13 \mathrm{kGy}$ & 10.3 & 71.1 & 6.87 \\
$26 \mathrm{kGy}$ & 10.0 & 74.8 & 7.46 \\
\hline
\end{tabular}

${ }^{\text {a }}$ Results obtained from refractive index detector based on polystyrene narrow standards calibration

${ }^{\mathrm{b}} \bigoplus_{\mathrm{M}}=\mathrm{M}_{\mathrm{w}} / \mathrm{M}_{\mathrm{n}}$

cross-linking process was also confirmed by the changes in weight-average molar mass $M_{w}$, which increased with radiation dose (Table 3; Fig. S2). It was well visible especially at the highest dose applied. On the other hand due to the degradation process, which occurred simultaneously, the numberaverage molar mass $M_{n}$ decreased slightly for the analyzed samples, and as a consequence the increase in molar mass distribution was observed. Taking under consideration the impact of radiation on $\mathrm{M}_{\mathrm{w}}$ and $\mathrm{M}_{\mathrm{n}}$ one could expect that 
cross-linking process is predominant in case of methylene chloride soluble part of studied materials.

The cross-linking induced by radiation is a well-known feature for PBS and starch. During irradiation of polysaccharides in the presence of oxygen the radicals located on the carbon atoms $\left(\mathrm{C}_{1}\right)$ of glucose units easily react with oxygen forming peroxide radicals. Those radicals can be quickly converted to the ketone group with the elimination of hydroperoxide radical $\left(\mathrm{HO}_{2}\right)^{\circ}$, which in many cases prevents further degradation of polysaccharide chain. This mechanism is unique for polysaccharides, and not observed for any other group of polymers. The influence of glycerol and urea cannot be excluded since they can form hydrogen bonds with starch thus changing its susceptibility to the degradation/cross-linking process [37]. Moreover, it was proved that the presence of such additives as glycerol, isopropanol and $t$-butanol exerts a protective effect by quenching $\mathrm{OH}$ radicals created during water radiolysis and forming the carbon-centered free radicals exhibiting lower reactivity toward polysaccharides [38].

Figure $2 \mathrm{~b}$ presents the radiation yield of oxygen $\left(\mathrm{GO}_{2}\right)$ in the function of radiation dose. The observed oxygen loss is related to the radiation-induced oxidation of the material and with a higher radiation dose, a lower oxygen diffusion into the polymer is detected [39]. Additionally, irradiation with the dose of $13 \mathrm{kGy}$ or $26 \mathrm{kGy}$ causes the consumption of all available oxygen, thus intensifying cross-linking processes, which is inhabited in the presence of oxygen due to its competition with the oxidative degradation.

Figure 3 shows the results from the TG analysis performed for the samples sterilized by the e-beam irradiation. It can be seen that the thermal degradation of each sample underwent through four weight loss stages. The first one

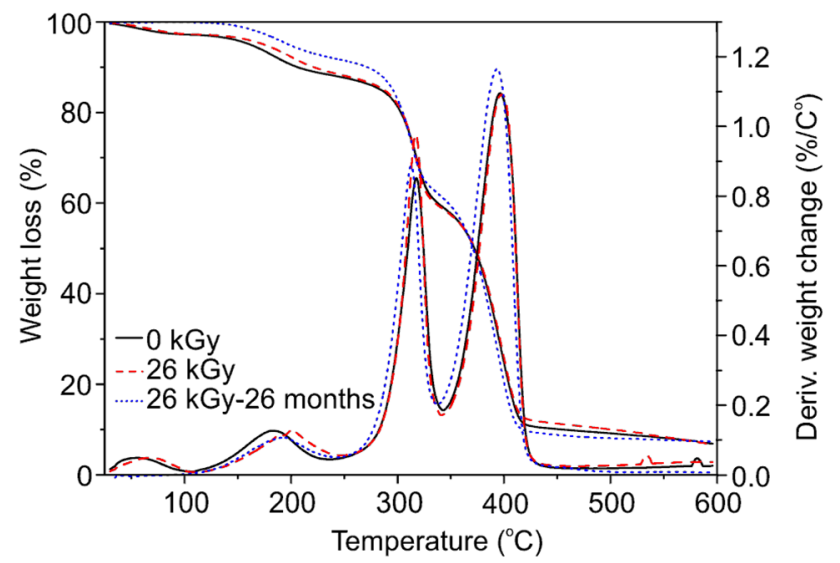

Fig. 3 Weight loss and derivatives weight change of the TPS/PBS sample before (black, solid line) and after the e-beam irradiation with a dose of $26 \mathrm{kGy}$ (red, dash line) determined by TG analysis. The blue, dotted line represents the same irradiated sample stored for 26 months (Color figure online) up to $120{ }^{\circ} \mathrm{C}$ can be assigned to the evaporation of water, and other volatile compounds present in TPS. The weight loss observed between 120 and $230{ }^{\circ} \mathrm{C}$ is attributed to the loss of urea and glycerol, which were used as plasticizers [40]. According to the data presented in Table 2, the content of water and plasticizers was stable for all the analyzed samples and reached about $10 \mathrm{wt} \%$. The third stage of thermal degradation relates to the starch decomposition, which began around $250{ }^{\circ} \mathrm{C}$ up to $340{ }^{\circ} \mathrm{C}$. The last degradation stage occurred from 350 to $450{ }^{\circ} \mathrm{C}$ and can be explained by the PBS chain degradation. Above $450{ }^{\circ} \mathrm{C}$ the carbonization process took place.

Based on the collected data, one can conclude, that the $\mathrm{T}_{\text {onset }}$ of TPS/PBS blend after e-beam irradiation practically did not change, which indicates that probably the chain scission occurred at a very low level or its effect was partially compensated by cross-linking. A very small decrease in thermal stability of the analyzed samples could be observed after 26 months of storage in air. It is especially evident for the sample irradiated with the highest dose. Moreover, it seems that after 26 months a part of the plasticizers evaporated (after its migration towards the surface) since the first weight loss stage did not occur. To summarize the thermal properties of the TPS/PBS blend treated with e-beam radiation, we can conclude that during sterilization process chain scission occurred, tough there might have been also some cross-link in the polymer chain. In general, material after sterilization was characterized by a higher crystallinity degree and unchanged thermal stability, however prolonged exposure to air may deteriorated its thermal properties.

\section{Mechanical and Barrier Properties Against Water}

The e-beam radiation had a strong impact on the mechanical properties of the analyzed samples (Fig. 4a-c). For all the applied dosages, Young's modulus of the tested films significantly increased. The polymer became more rigid and was characterized by lower tensile strength and elongation at break than the control sample. The changes in the blend structure had a positive effect on its barrier properties, since the irradiation doses higher than $5 \mathrm{kGy}$ resulted in a reduction of water vapor permeability by about $14 \%$ and $10 \%$, respectively (Fig. 4d). Additionally, we tested the mechanical parameters of neat PBS before and after irradiation with the e-beam (Fig. 4e, f) to investigate whether the observed reduction in tensile strength is related to the starch or PBS degradation. As can be seen in Fig. 4e, $\mathrm{f}$ the mechanical properties of PBS did not deteriorate after irradiation-they remained the same or even got slightly better compared to the reference sample. In that case, the cross-linking process occurred, however, according to the literature, a stronger cross-linking effect requires higher radiation doses [41]. One can conclude, that in general the e-beam radiation reduces 

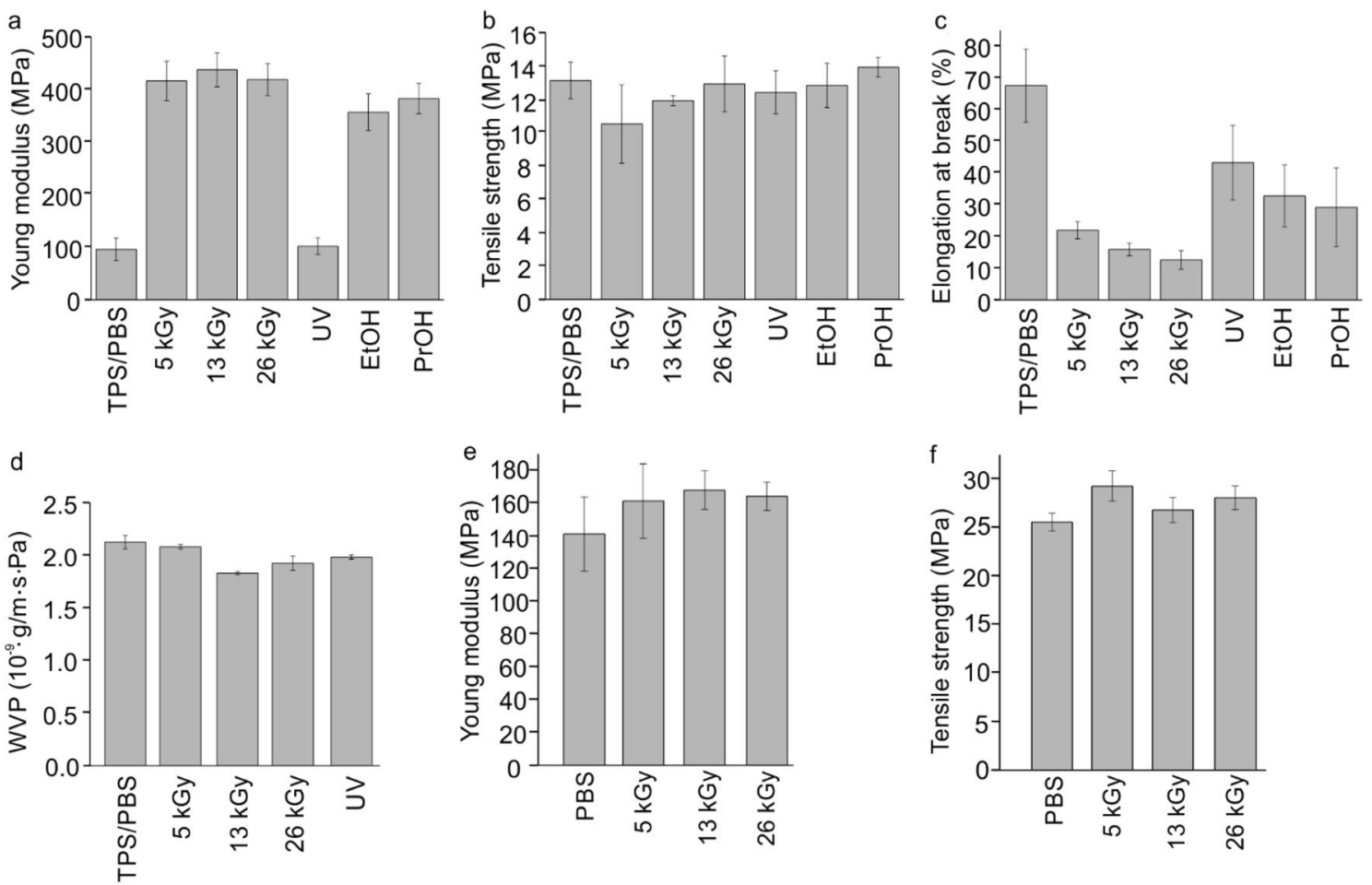

Fig. 4 Mechanical properties (a-c) and water vapor permeability (WVP, d) of the TPS/PBS blend before and after sterilization, and $\mathbf{e}$, $\mathbf{f}$ mechanical properties of PBS before and after irradiation with different doses of the e-beam

the tensile strength of the TPS/PBS blend mainly due to the chain scission of starch. However it seems that the lower doses of the e-beam irradiation may have stronger effect on degradation than the higher ones. Other sterilization methods, performed in the presence of ethanol and isopropanol resulted in an increase of Young's modulus by almost 3.5 times in comparison to the control sample. This effect was caused mainly by leaching of plasticizer to the alcohol solution. In that case the material became less elastic and the reduction of elongation at break was observed. It seems that only the UV radiation did not change significantly the mechanical parameters of the TPS/PBS blend, and additionally slightly enhanced its barrier properties against water.

\section{Morphology of the Blends}

The morphology of the blend strongly influence its mechanical properties, therefore a microstructure of the TPS/PBS samples was analyzed by SEM. Figure 5 shows the SEM microphotographs of a non-irradiated TPS/PBS and its samples treated with the e-beam. As shown in Fig. 5a, b, starch and PBS created two immiscible phases. The blend exhibited a matrix-dispersed phase morphology, particles of starch retain their granular shape, and are dispersed in the PBS continuous matrix [42]. The difference in a polarity between a polyester and a polysaccharide causes difficulties in obtaining the miscible system [43]. Moreover, on the surface some tetragonal crystals can be observed-it is possible that they are formed by urea. In Fig. 5b, we can also observe small particles located on the polymer surface. We suspect that they can be made of the crystalline starch since the similar structures of starch were already observed by several authors [44]. After irradiation with the e-beam (Fig. 5c-h) morphology of the blend did not change significantly, however, in some regions of the sample, the small cavities/holes could be observed. It should be mentioned, that the number of those holes did not change an increase of the radiation dose. These results suggest that the radiation caused a partial damage to the blend surface, however, the polymer phase integrity has been maintained.

\section{Biodegradation Studies}

Starch degradation occurs as a consequence of enzymatic attack at the glycosidic linkages between the glucose units. The main enzymes responsible for that process are amylolytic enzymes such as: $\alpha$ - and $\beta$-amylase, glucoamylase, isoamylase, pullulanase, exo-1,4- $\alpha$-d-glucanase, $\alpha$-d-glycosidase as well as cyclomaltodextrin-D-glucotransferase [45]. In our studies we examined the degradation rate of the irradiated TPS/PBS blend in the presence of a commercial $\alpha$-amylase and crude amylase synthesized in $B$. subtilis cultures. For 

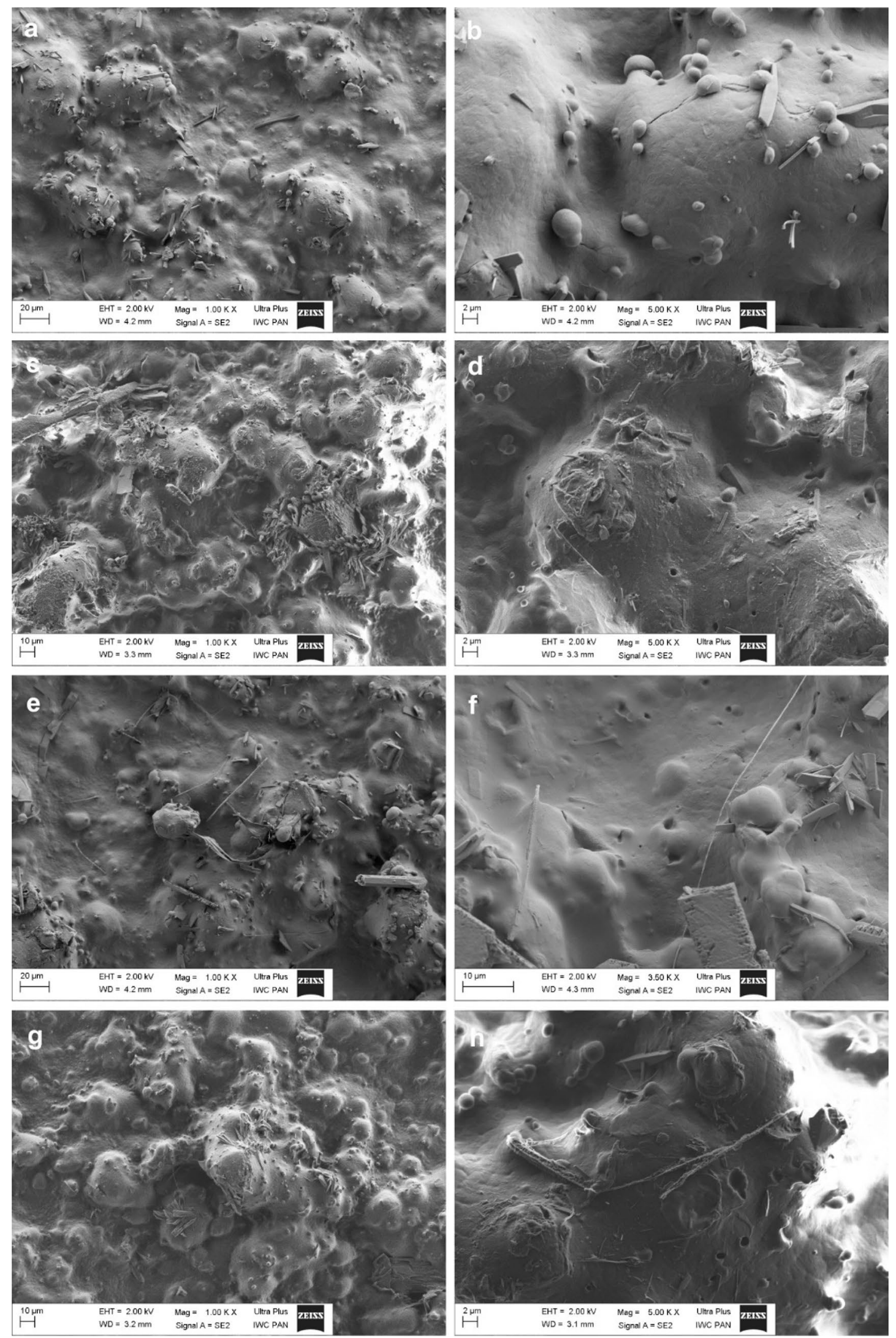

Fig. 5 SEM images of the neat TPS/PBS blend (a, b) and its samples irradiated with different doses of the e-beam: $5 \mathrm{kGy}(\mathbf{c}, \mathbf{d}), 13 \mathrm{kGy}(\mathbf{e}, \mathbf{f})$ and $26 \mathrm{kGy}(\mathbf{g}, \mathbf{h})$ 
industrial application the purification of $\alpha$-amylase is not required, however, for the pharmaceutical and biomedical purposes such process is obligatory [46]. For that reason, in our work we used both types of this degradation agents: pure $\alpha$-amylase and lyophilizate of the post-culture liquid from $B$. subtilis.

\section{Degradation in the Presence of a Commercial a-Amylase}

The simplest method to investigate the changes occurring during polymer degradation is the gravimetric method, where the sample is weighed before and after degradation and a percentage of the weight loss is calculated. For TPS and its blends the results obtained from this method may be overstated due to the high percentage of water and plasticizers which they typically contain. That is why, in the

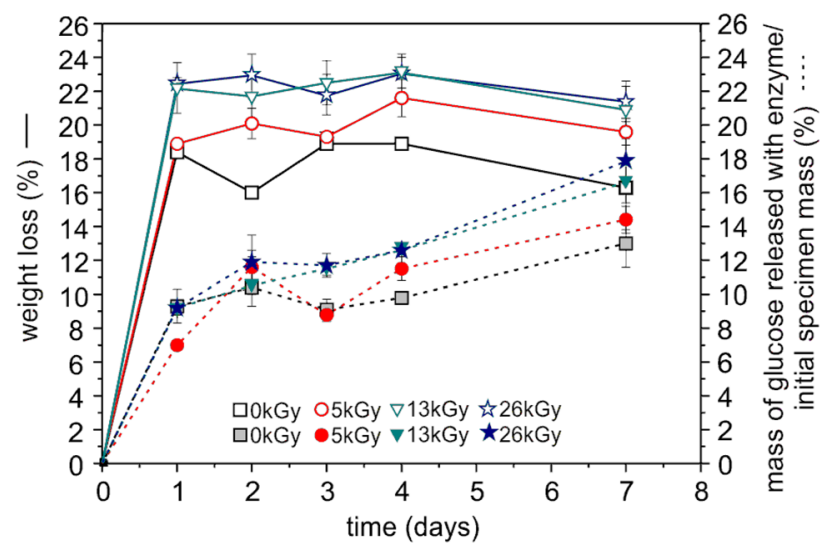

Fig. 6 Weight loss (solid line and empty marker) and mass of glucose released to the solution (dashed line and filled marker) during the TPS/PBS blend degradation, as a function of degradation time
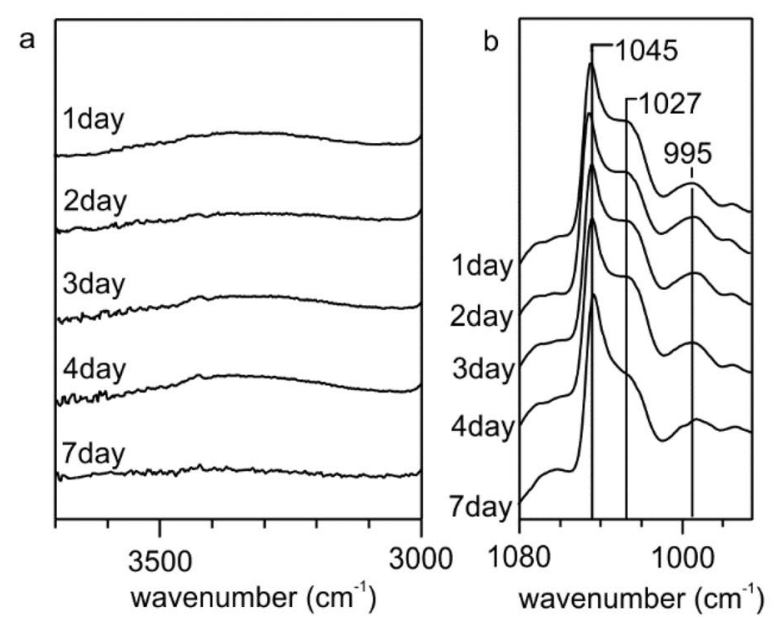

Fig. 7 FTIR spectra of the TPS/PBS blend: irradiated with a dose of $13 \mathrm{kGy}$ subjected to degradation, in the region of a $3700-3000 \mathrm{~cm}^{-1}$ and b $1080-960 \mathrm{~cm}^{-1}$; non-irradiated and irradiated with different presented studies we showed the degree of degradation of the TPS/PBS blend before and after radiation, expressed as weight loss and mass of glucose released to the degradation solution. As can be seen from Fig. 6, it seems that the irradiation caused an acceleration of the sample degradation, regardless of the adopted evaluation criterion. Probably, the small holes observed in the SEM images of the irradiated samples, facilitated a penetration of water into the sample thus making a degradation of starch more effective. Those results are in agreement with the literature [47].

The amount of polysaccharides released to the solution was also determined (Table S1 in Supplementary Material), by a previously described colorimetric method [24]. It was found that the quantity of starch released in all degradation experiments was small and not exceeded $0.30 \%$. This finding allows for a conclusion that the estimated weight loss was associated mainly with the release of glucose and plasticizers. Since initially the investigated blend contained $50 \mathrm{wt} \%$ of PBS, $35 \mathrm{wt} \%$ of starch, $12.5 \mathrm{wt} \%$ of urea and $2.5 \mathrm{wt} \%$ of glycerol, it seems that after 7 days of degradation, a maximum half of starch amount has been decomposed (18\% in case of sample irradiated with a dose of $26 \mathrm{kGy}$, calculated by the mass of glucose method as shown in Fig. 6) and we assume that the rest of it was still present in the PBS matrix. Probably, this remaining starch phase is strongly interpenetrated with the insoluble PBS component, which makes it difficult for enzymes to reach its molecules.

To specify the surface changes of the TPS/PBS blend after degradation, starch infrared absorption bands characteristic of the $\mathrm{C}-\mathrm{O}-\mathrm{C}$ (at $1027 \mathrm{~cm}^{-1}$ and $995 \mathrm{~cm}^{-1}$ (Fig. 7a) and $-\mathrm{OH}$ groups (in the range of $3700-3000 \mathrm{~cm}^{-1}$, Fig. 7b) were evaluated. For all the examined samples, regardless of the applied radiation dose (here we present the FTIR spectra only for the
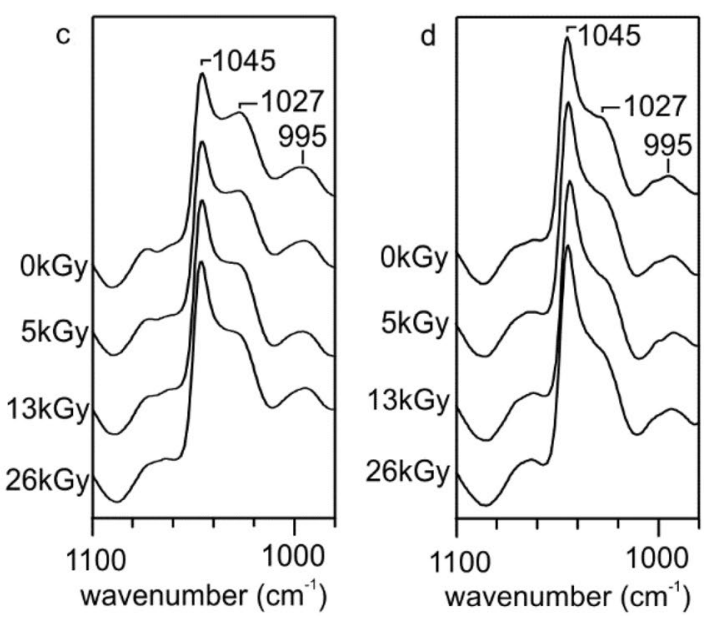

doses of the e-beam, after 1 day (c) and 7 days (d) of degradation, in the region of $1100-980 \mathrm{~cm}^{-1}$ 
Fig. 8 DSC thermograms of the TPS/PBS blends after 7 days of enzymatic degradation: $\mathbf{a}$ the first heating cycle, $\mathbf{b}$ the cooling cycle, and $\mathbf{c}$ the second heating cycle. $\mathrm{T}_{\mathrm{m}}, \mathrm{T}_{\mathrm{c}}$ and $\Delta \mathrm{H}_{\mathrm{m}}$ refer to the melting temperatures, melt crystallization temperature and enthalpy of melting, respectively

samples treated with a dose of $13 \mathrm{kGy}$ ), a starch degradation from the polymer surface began immediately, without any prolonged induction period. One can clearly observe that the intensity of the analyzed signals decreased with the degradation time, and after 7 days the signal characteristic of the $\mathrm{OH}$ group was barely detected.

Moreover, as can be seen in Fig. 7c, d, at the beginning an increase in the applied e-beam dose accelerated starch degradation, however, after 7 days of incubation this phenomenon was negligible. Those observations were also supported by the SEM pictures (Fig. S3 in Supplementary Material), which showed that the changes in the surface topography of the samples non-irradiated and irradiated with a dose of $26 \mathrm{kGy}$ after 7 days of enzyme action were similar. Both analyzed films had small holes on their surface which arise from a degradation of starch.

After 7 days of enzymatic degradation all samples were tested by means of DSC. Melting temperature remained unchanged, however its enthalpy of melting was gradually increased with the increasing radiation dose (Fig. 8a). This was expected due to the fact, that during hydrolysis the amorphous phase of aliphatic polyesters degrades more rapidly than the crystalline phase [48]. The radiation-induced chain scission of PBS had also an effect on the melt crystallization temperature (Fig. 8b), which was shifted to the lower region when the radiation dose increased. One can expect that, the oligomers formed during degradation, hindered crystallization of the PBS. According to the literature, the polymer with lower molecular weight exhibits much lower $\mathrm{T}_{\mathrm{c}}$ and the crystallization is much slower. Moreover, the nucleation density increases with increasing molecular weight [49]. In our case biodegradation and radiation-induced chain scission probably caused lowering of the PBS molecular weight and as a consequence we observed a decrease in $T_{c}$. Interestingly, a double peak from melt-recrystallization process of PBS (Fig. 8c) appeared only for the non-irradiated sample and that subjected to the lowest radiation dose. For the rest of the samples the first melting peak (assigned as $\mathrm{T}_{\mathrm{m} 1}$ in the Fig. 8c) was not detected, which suggest that the melt-recrystallization process did not occur. Instead, a cold crystallization can be observed, as evidence by the occurrence of a small exotherm $(T=100$ and $98{ }^{\circ} \mathrm{C}$ for the samples irradiated with 13 and $26 \mathrm{kGy}$, respectively) just before the melting peak.
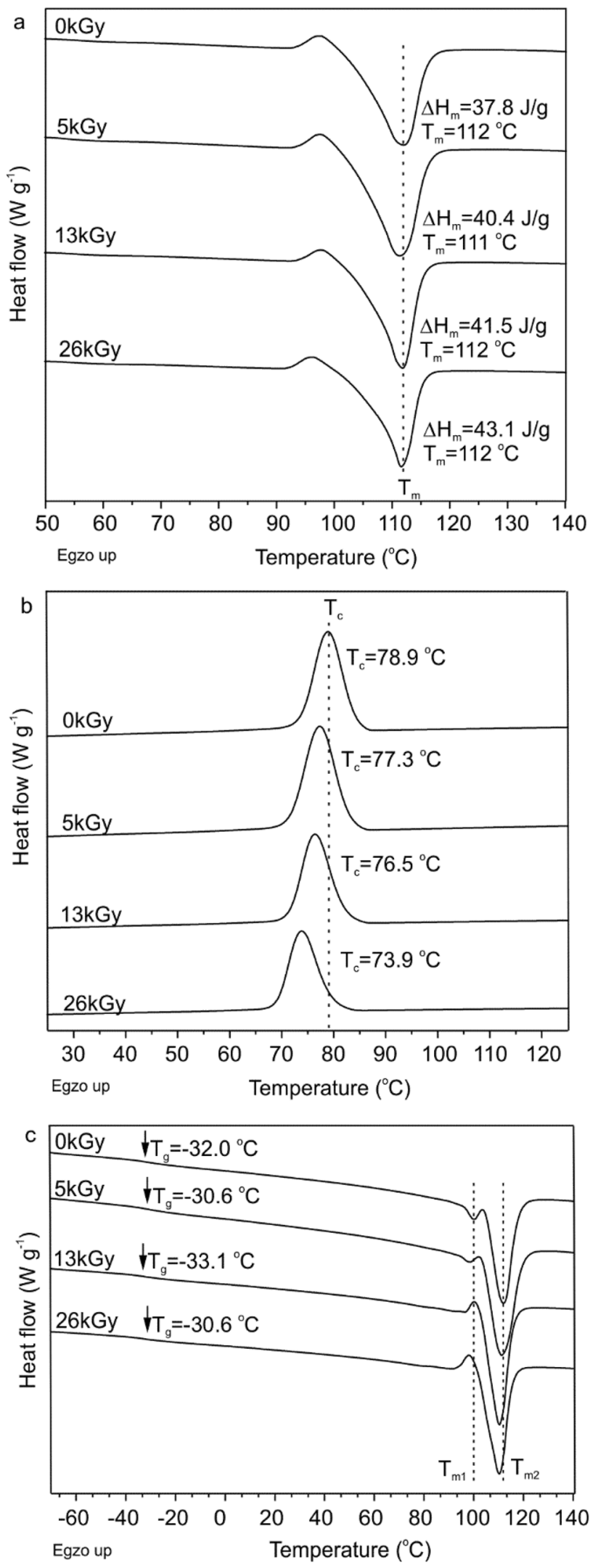


\section{Degradation in the Presence of Crude Amylase Synthesized in B. subtilis Cultures}

The Bacillus species are considered as the most important producers of $\alpha$-amylase and are widely used in the industry, for example in the solid state fermentation [50]. Except of starch degradation, some Bacillus species like B. pumilus and $B$. subtilis can also be active in the aliphatic polyester decomposition, because they are present in their degrading microbiota in natural environments under mesophilic conditions [51].

The $\alpha$-amylase production by $B$. subtilis bacteria was conducted in a culture medium containing $2 \%$ of soluble starch, yeast extract and peptone. The optimum temperature and time of incubation was $37^{\circ} \mathrm{C}$ and $72 \mathrm{~h}$, respectively (Fig. S4 in Supplementary Material). The post-culture liquid (supernatant), with the highest amylolytic activity $\left(0.27 \mathrm{U} \mathrm{mL}^{-1}\right)$ was used as a degrading agent for the blend subjected to the e-beam radiation. The oamylase produced by $B$. subtilis cells showed the highest activity at $50{ }^{\circ} \mathrm{C}$, however, decreased rapidly with time and even after $1 \mathrm{~h}$ of incubation $10 \%$ of that activity was lost. Thus the polymer degradation was conducted at slightly lower temperature of $37^{\circ} \mathrm{C}$.

As can be seen in Fig. 9, the investigated polymer blends underwent fast degradation in the first $24 \mathrm{~h}$ since in that timespan the weight loss measured for all samples exceeded $20 \%$. It seems, that a decomposition of the sample irradiated with the highest dose of the e-beam was the fastest and after 7 days of incubation it lost $28 \%$ of its initial weight. Moreover, these results shows, that the crude amylase from $B$. subtilis cultivation was more efficient in degradation of the TPS/PBS blend than pure $\alpha$-amylase, even if its activity was much lower. The post-culture liquid is a mixture of different

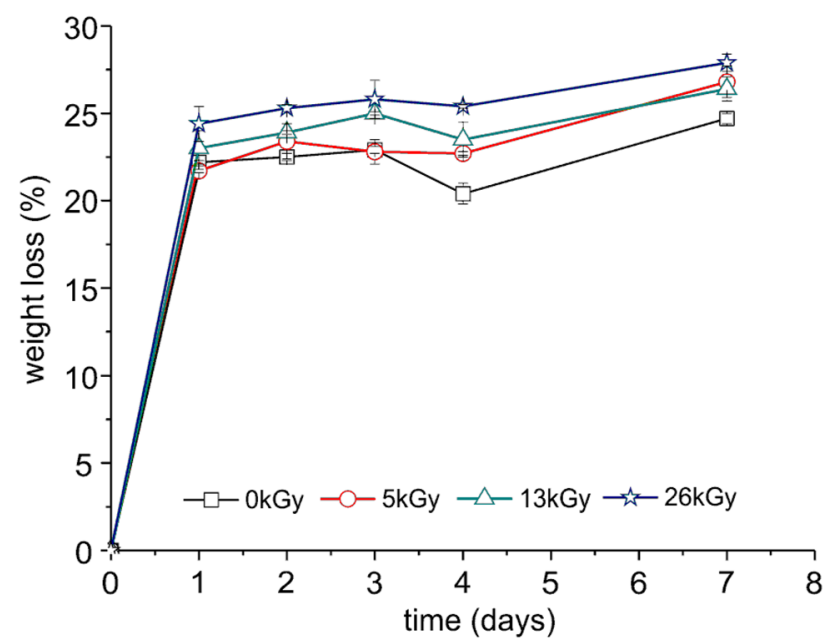

Fig. 9 Weight loss of the studied TPS/PBS blend before and after irradiation by different doses of the e-beam as a function of degradation time in the presence of crude amylase isoenzymes of amylases, which are able to hydrolyze starch in different chain position. On the other hand, $\alpha$-amylase is responsible only for decomposition of the $\alpha-1,4$-glycosidic linkages. This can explain, why using lower-purity enzyme resulted in a higher degradation degree.

DSC analysis (Table 4) of the samples after degradation with crude amylase showed an increase of the glass temperature at higher radiation doses, which is indicative of a partial degradation of the PBS amorphous phase. This effect can be also related to the leaching of plasticizers, however, such a rise of the $T_{g}$ value was not observed after degradation with $\alpha$-amylase. For all samples degraded with a crude amylase, the enthalpy of fusion was higher in comparison to the undegraded sample by approximately $11 \mathrm{~J} \mathrm{~g}^{-1}$. The most significant changes were observed in the melt crystallization temperature, which decreased with an increasing radiation dose. The same effect was also observed during experiments with $\alpha$-amylase and can be explained in the same way by the creation of PBS oligomers during degradation.

In our studies we evaluated a degradability of the TPS/ PBS blend under the influence of $B$. subtilis cells. Such experiments were performed on the Petri dishes filled with mineral medium (nutrient-salts agar, without any additional carbon source). The weight loss, thermal and structural properties were examined for each material after 1, 2 and 3 weeks of incubation at $37^{\circ} \mathrm{C}$ (Table 5). This variant of degradation forces microorganism to use the TPS/PBS blend components as their only source of carbon for cell proliferation.

Similarly to the results obtained with amylase enzyme, after 1 week of degradation about $26.6 \%$ of the blend was degraded. During the second week the weight loss of the sample did not change significantly, however longer degradation increased its value to almost $41 \%$. The melting temperature of the PBS crystalline phase was stable and close to $T_{m}$ of the non-degraded sample. Moreover, during the incubation, the $\Delta \mathrm{H}_{\mathrm{m}}$ value was gradually increased which confirms a degradation of the PBS amorphous phase and is in a good agreement with the results obtained during a liquid degradation. The melt crystallization temperature during

Table 4 Thermal properties of the non-irradiated and irradiated TPS/ PBS blend after 7 days of degradation in the presence of crude amylase

\begin{tabular}{lllll}
\hline Sample & $\mathrm{T}_{\mathrm{g}}\left({ }^{\circ} \mathrm{C}\right)$ & $\mathrm{T}_{\mathrm{m}}\left({ }^{\circ} \mathrm{C}\right)$ & $\Delta \mathrm{H}_{\mathrm{m}}\left(\mathrm{J} \mathrm{g}^{-1}\right)$ & $\mathrm{T}_{\mathrm{c}}\left({ }^{\circ} \mathrm{C}\right)$ \\
\hline $0 \mathrm{kGy}$ & -33.5 & 112 & 43.0 & 80.5 \\
$5 \mathrm{kGy}$ & -31.8 & 112 & 40.8 & 78.1 \\
$13 \mathrm{kGy}$ & -26.7 & 111 & 41.5 & 76.8 \\
$26 \mathrm{kGy}$ & -29.7 & 112 & 43.4 & 74.4 \\
\hline
\end{tabular}

$\mathrm{T}_{\mathrm{g}}$ and $\mathrm{T}_{\mathrm{m}}$ were determined from the 2 nd and $1 \mathrm{st}$ heating scan, respectively; $T_{c}$ was determined based on the cooling cycle. $T_{g}, T_{m}$, $\mathrm{T}_{\mathrm{c}}$ and $\Delta \mathrm{H}_{\mathrm{m}}$ refer to the glass temperature, melting temperature, melt crystallization temperature and enthalpy of melting, respectively 
Table 5 Thermal properties of the TPS/PBS after 1, 2 and 3 weeks of degradation on the Petri dish in the presence of $B$. subtilis cells

\begin{tabular}{llllllll}
\hline $\begin{array}{l}\text { Degradation } \\
\text { time (weeks) }\end{array}$ & Weight loss $(\%)$ & $\mathrm{T}_{\mathrm{g}}\left({ }^{\circ} \mathrm{C}\right)$ & $\mathrm{T}_{\mathrm{m}}\left({ }^{\circ} \mathrm{C}\right)$ & $\Delta \mathrm{H}_{\mathrm{m}}\left(\mathrm{J} \mathrm{g}^{-1}\right)$ & $\mathrm{T}_{\mathrm{c}}\left({ }^{\circ} \mathrm{C}\right)$ & $\mathrm{T}_{\text {onset3 }}\left({ }^{\circ} \mathrm{C}\right)$ & $\mathrm{T}_{\text {onset4 }}\left({ }^{\circ} \mathrm{C}\right)$ \\
\hline 1 & $26.6 \pm 3.3$ & -26.3 & 111 & 41.0 & 78.1 & 298 & 373 \\
2 & $27.8 \pm 0.5$ & -33.3 & 111 & 44.5 & 78.7 & - & - \\
3 & $40.9 \pm 3.1$ & -29.3 & 112 & 53.4 & 81.5 & 280 & 370 \\
\hline
\end{tabular}

$\mathrm{T}_{\mathrm{g}}$ (glass transition), $\mathrm{T}_{\mathrm{m}}$ (melting temperature) and $\Delta \mathrm{H}_{\mathrm{m}}$ (enthalpy of melting) were determined by the 2nd and 1 st heating scan, respectively. $\mathrm{T}_{\mathrm{c}}$ (melt crystallization temperature) was determined by cooling scan.; $\mathrm{T}_{\text {onset3 }}$ and $\mathrm{T}_{\text {onset } 4}$ relate to the degradation of TPS and PBS in the polymer blend, respectively

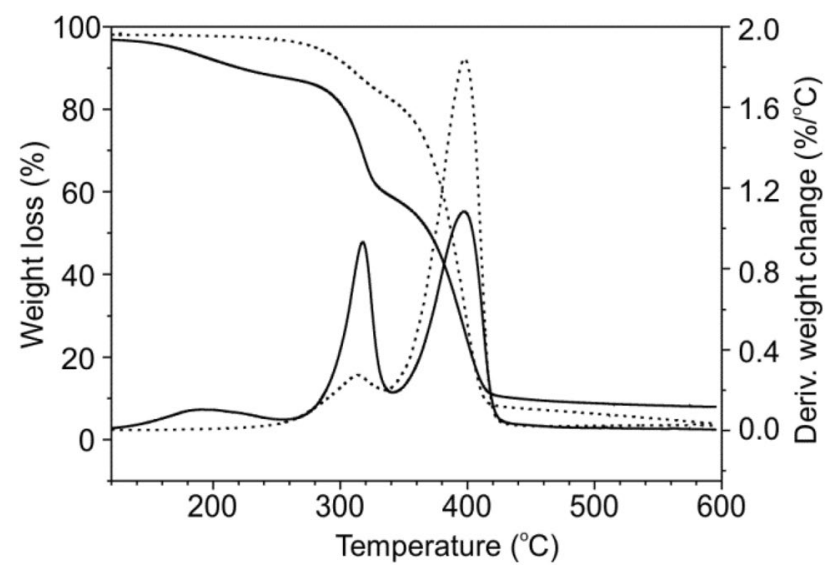

Fig. 10 TG analysis of the TPS/PBS blend before (solid line) and after (dashed line) 3 weeks of degradation in the presence of $B$. subtilis cells on the agar plate

cooling increased to $78-81^{\circ} \mathrm{C}$, which can be explained by the presence of oligomers and their greater mobility and ease of rearrangement into crystal domains. From the TG thermogram (Fig. 10) one can see that after 3 weeks of degradation the sample contained mainly the PBS phase and the fraction of starch was much smaller than at the beginning of the experiment - this finding is supported by the weight loss around $300{ }^{\circ} \mathrm{C}$ getting smaller after degradation.

\section{Conclusion}

The effect of the e-beam radiation and other commonly used sterilization techniques on the structural, morphological, and biodegradation properties of the TPS/PBS blend has been explored. It turned out that all the applied sterilization methods effectively eliminated the growth of yeast and molds, while only the e-beam irradiation decreased the bacterial microflora below $1.0 \log \mathrm{cfu} \mathrm{mL}^{-1}$. In addition, according to the SEM and FTIR analyses, the applied e-beam radiation doses did not cause significant changes on the surface of the investigated material. On the other hand, they improved barrier properties of the material against water vapor and allowed faster decomposition in the presence of a commercial $\alpha$-amylase and enzymes of microbial origin (derived from wild strain $B$. subtilis). This means that during the irradiation both degradation and cross-linking processes took place, which additionally has been confirmed by a gas chromatography on the basis of the hydrogen radiation yield. All the analyzed sterilization methods worsened the mechanical properties of the tested material, since the polymer blend became more rigid and less flexible, however, the UV sterilization had the lowest impact on the mechanical parameters. The obtained results revealed that among all the studied techniques, the e-beam irradiation is the most promising for sterilization of the TPS/PBS blend due to its high efficiency in microorganism elimination, positive effect on both the barrier properties against water and degradation of the blend. The other methods, which did not give such good results, will be the subject of further research, where a combination of different techniques will be studied.

Acknowledgements This work was financially supported by National Science Centre of Poland (MINIATURA-1), Grant Number DEC2017/01/X/ST8/00883 entitled: "Effect of selected sterilization methods on structural, mechanical and microbiological properties of thermoplastic starch blends used in the food and medicine packaging industry".

Open Access This article is licensed under a Creative Commons Attribution 4.0 International License, which permits use, sharing, adaptation, distribution and reproduction in any medium or format, as long as you give appropriate credit to the original author(s) and the source, provide a link to the Creative Commons licence, and indicate if changes were made. The images or other third party material in this article are included in the article's Creative Commons licence, unless indicated otherwise in a credit line to the material. If material is not included in the article's Creative Commons licence and your intended use is not permitted by statutory regulation or exceeds the permitted use, you will need to obtain permission directly from the copyright holder. To view a copy of this licence, visit http://creativecommons.org/licenses/by/4.0/.

\section{References}

1. The European Directorate for the Quality of Medicines and HealthCare (EDQM) (2019) Methods of sterilization in The International Pharmacopeia, 9th edn. World Health Organization, Geneva

2. Lambert BJ, Mendelson TA, Craven MD (2011) Radiation and ethylene oxide terminal sterilization experiences with drug eluting 
stent products. AAPS PharmSciTech 12:1116-1126. https://doi. org/10.1208/s12249-011-9644-8

3. Scaramuzza N, Cigarini M, Mutti P, Berni E (2020) Sanitization of packaging and machineries in the food industry: effect of hydrogen peroxide on ascospores and conidia of filamentous fungi. Int J Food Microbiol 316:108421-108431. https://doi. org/10.1016/j.ijfoodmicro.2019.108421

4. Dai Z, Ronholm J, Tian Y, Sethi B, Cao X (2016) Sterilization techniques for biodegradable scaffolds in tissue engineering applications. J Tissue Eng 7:1-13. https://doi.org/10.1177/2041731416 648810

5. Porto BG, Napolitano KM, Borrely CM (2018) Gamma radiation effects in packaging for sterilization of health products and their constituents paper and plastic film. Radiat Phys Chem 142:23-28. https://doi.org/10.1016/j.radphyschem.2016.12.019

6. Iuliano A, Nowacka M, Rybak K, Rzepna M (2020) The effects of electron beam radiation on material properties and degradation of commercial PBAT/PLA blend. J Appl Polym Sci 137:48462-48472. https://doi.org/10.1002/app.48462

7. Zhang K, Perussello CA, Milosavljević V, Cullen PJ, Sun D-W, Tiwari BK (2019) Diagnostics of plasma reactive species and induced chemistry of plasma treated foods. Crit Rev Food Sci Nutr 59:812-825. https://doi.org/10.1080/10408 398.2018.1564731

8. Massey LK (2005) Introduction to sterilization methods. In: Massey LK (ed) The effect of sterilization methods on plastics and elastomers. William Andrew, Inc., Elsevier, Norwich

9. Khan B, Niazi MBK, Samin G, Jahan Z (2017) Thermoplastic starch: a possible biodegradable food packaging materiala review. J Food Process Eng 40(e12447):1-17. https://doi. org/10.1111/jfpe. 12447

10. Da Róz A, Carvalho A, Gandini A, Curvelo A (2006) The effect of plasticizers on thermoplastic starch compositions obtained by melt processing. Carbohydr Polym 63:417-424. https://doi. org/10.1016/j.carbpol.2005.09.017

11. Labus K, Trusek-Holownia A, Semba D, Ostrowska J, Tynski P, Bogusz J (2018) Biodegradable polylactide and thermoplastic starch blends as drug release device-mass transfer study. Pol J Chem Technol 20:75-80. https://doi.org/10.2478/ pjct-2018-0011

12. Ribba L, Garcia N, D'Accorso N, Goyanes S (2017) Disadvantages of starch-based materials, feasible alternatives in order to overcome these limitations. In: Vilar M, Barbosa SE, Garcia MA, Castillo LA, Lopez OV (eds) Starch-based materials in food packaging: processing, characterization and applications. Academic, London, pp 37-76

13. Liu W, Liu S, Wang Z, Liu J, Dai B, Chen Y, Zeng G (2019) Preparation and characterization of compatibilized composites of poly(butylene adipate-co-terephthalate) and thermoplastic starch by two-stage extrusion. Eur Polym J 122:109369-109377. https ://doi.org/10.1016/j.eurpolymj.2019.109369

14. Lekube BM, Fahrngruber B, Kozich M, Wastyn M, Burgstaller C (2019) Influence of processing on the mechanical properties and morphology of starch-based blends for film applications. J Appl Polym Sci 136:47990-47998. https://doi.org/10.1002/app.47990

15. Guarás MP, Alvarez VA, Ludueña LN (2015) Processing and characterization of thermoplastic starch/polycaprolactone/compatibilizer ternary blends for packaging applications. J Polym Res 22:165-180. https://doi.org/10.1007/s10965-015-0817-0

16. Correa AC, Carmona VB, Simão JA, Capparelli Mattoso LH, Marconcini JM (2017) Biodegradable blends of urea plasticized thermoplastic starch (UTPS) and poly( $\varepsilon$-caprolactone) (PCL): morphological, rheological, thermal and mechanical properties. Carbohydr Polym 167:177-184. https://doi.org/10.1016/j.carbp ol.2017.03.051
17. Yun IS, Hwang SW, Shim JK, Seo KH (2016) A study on the thermal and mechanical properties of poly (butylene succinate)/ thermoplastic starch binary blends. Int J Precis Eng Manuf Green Technol 3:289-296. https://doi.org/10.1007/s40684-016-0037-z

18. Boonprasith P, Wootthikanokkhan J, Nimitsiriwat N (2013) Mechanical, thermal, and barrier properties of nanocomposites based on poly(butylene succinate)/thermoplastic starch blends containing different types of clay. J Appl Polym Sci 130:11141123. https://doi.org/10.1002/app.39281

19. Collazo-Bigliardi S, Ortega-Toro R, Chiralt A (2019) Using grafted poly ( $\varepsilon$-caprolactone) for the compatibilization of thermoplastic starch-polylactic acid blends. React Funct Polym 142:2535. https://doi.org/10.1016/j.reactfunctpolym.2019.05.013

20. Palai B, Biswal M, Mohanty S, Nayak SK (2019) In situ reactive compatibilization of polylactic acid (PLA) and thermoplastic starch (TPS) blends; synthesis and evaluation of extrusion blown films thereof. Ind Crops Prod 141:111748. https://doi. org/10.1016/j.indcrop.2019.111748

21. Fourati Y, Tarrés Q, Mutjé P, Boufi S (2018) PBAT/thermoplastic starch blends: effect of compatibilizers on the rheological, mechanical and morphological properties. Carbohydr Polym 199:51-57. https://doi.org/10.1016/j.carbpol.2018.07.008

22. Nowacka M, Rybak K, Wiktor A, Mika A, Boruszewski P, Woch J, Przybysz K, Witrowa-Rajchert D (2018) The quality and safety of food contact materials - paper and cardboard coated with paraffin emulsion. Food Control 93:183-190. https://doi.org/10.1016/j. foodcont.2018.06.011

23. Xiao Z, Storms R, Tsang A (2006) A quantitative starch-iodine method for measuring alpha-amylase and glucoamylase activities. Anal Biochem 351:146-148. https://doi.org/10.1016/j. ab.2006.01.036

24. Kundys A, Ostrowska J, Chojnacka U, Grodzka Z, Lange A, Paluch M (2018) Enzymatic degradation of poly(butylene succinate)/thermoplastic starch blend. J Renew Mater 6:611-618. https ://doi.org/10.32604/jrm.2018.00134

25. Ansari IA, Datta AK (2003) An overview of sterilization methods for packaging materials used in aseptic packaging systems. Chem Eng Res Des 81:57-65. https://doi.org/10.1205/09603 0803765208670

26. Moghaddam Arjmand M, Rezaee A, Nasseri S, Eshraghi S (2015) Effects of ethanol on the electrochemical removal of Bacillus subtilis spores from water. J Environ Health Sci Eng 13:78-84. https ://doi.org/10.1186/s40201-015-0229-4

27. Mazzola PG, Jozala AF, Novaes LC, de Moriel L, Penna P (2009) Minimal inhibitory concentration (MIC) determination of disinfectant and/or sterilizing agents. Braz J Pharm Sci 45:241-248. https://doi.org/10.1590/S1984-82502009000200008

28. Setlow P (2001) Resistance of spores of Bacillus species to ultraviolet light. Environ Mol Mutagen 38:97-104. https://doi. org/10.1002/em.1058

29. De Lara J, Fernández PS, Periago PM, Palop A (2002) Irradiation of spores of Bacillus cereus and Bacillus subtilis with electron beams. Innov Food Sci Emerg Technol 3:379-384. https://doi. org/10.1016/S1466-8564(02)00053-X

30. Helfinstine SL, Vargas-Aburto C, Uribe RM, Woolverton CJ (2005) Inactivation of Bacillus endospores in envelopes by electron beam irradiation. Appl Environ Microbiol 71:7029-7032. https://doi.org/10.1128/AEM.71.11.7029-7032.2005

31. Ostrowska J, Sadurski W, Paluch M, Tyński P, Bogusz J (2019) The effect of poly(butylene succinate) content on the structure and thermal and mechanical properties of its blends with polylactide. Polym Int 68:1271-1279. https://doi.org/10.1002/pi.5814

32. Bajer D, Kaczmarek H (2010) Study of the influence OV UV radiation on biodegradable blends based on chitosan and starch. Prog Chem Appl Chitin Deriv 15:17-24 
33. Kizil R, Irudayaraj J, Seetharaman K (2002) Characterization of irradiated starches by using FT-Raman and FTIR spectroscopy. J Agric Food Chem 50:3912-3918. https://doi.org/10.1021/jf011 $652 \mathrm{p}$

34. Versino F, García MA (2018) Starch films for agronomic applications: comparative study of urea and glycerol as plasticizers. Int J Environ Agric Biotechnol 3:1854-1864. https://doi.org/10.22161 /ijeab/3.5.38

35. Wang X, Zhou J, Li L (2007) Multiple melting behavior of poly(butylene succinate). Eur Polym J 43:3163-3170. https://doi. org/10.1016/j.eurpolymj.2007.05.013

36. Głuszewski W, Zagórski ZP, Rajkiewicz M (2014) Synergistic effects in the processes of crosslinking of elastomers. Radiat Phys Chem 94:36-39. https://doi.org/10.1016/j.radphysche m.2013.07.019

37. Naznin M, Abedin MZ, Khan MA, Gafur MA (2012) Influence of Acacia catechu\&nbsp; extracts and urea and gamma irradiation on the mechanical properties of starch/PVA-based material. Int Sch Res Notices 2012:1-8. https://doi.org/10.5402/2012/348685

38. Khandal D, Aggarwal M, Suri G, Coqueret X (2015) Electron beam irradiation of maltodextrin and cinnamyl alcohol mixtures: influence of glycerol on cross-linking. Carbohydr Polym 117:150 159. https://doi.org/10.1016/j.carbpol.2014.08.115

39. Głuszewski W, Stasiek A, Raszkowska-Kaczor A, Kaczor D (2018) Effect of polyethylene cross-linking on properties of foams. Nukleonika 63:81-85. https://doi.org/10.2478/nuka-2018-0010

40. Ren J, Dang KM, Pollet E, Avérous L (2018) Preparation and characterization of thermoplastic potato starch/halloysite nanobiocomposites: effect of plasticizer nature and nanoclay content. Polymers 10:808. https://doi.org/10.3390/polym10080808

41. Suhartini M, Mitomo H, Yoshii F, Nagasawa N, Kume T (2001) Radiation crosslinking of poly(butylene succinate) in the presence of inorganic material and its biodegradability. J Polym Environ 9:163-171. https://doi.org/10.1023/A:1020417422032

42. Garalde RA, Thipmanee R, Jariyasakoolroj P, Sane A (2019) The effects of blend ratio and storage time on thermoplastic starch/ poly(butylene adipate-co-terephthalate) films. Heliyon 5:e01251. https://doi.org/10.1016/j.heliyon.2019.e01251

43. Zeng J-B, Jiao L, Li Y-D, Srinivasan M, Li T, Wang Y-Z (2011) Bio-based blends of starch and poly(butylene succinate) with improved miscibility, mechanical properties, and reduced water absorption. Carbohydr Polym 83:762-768. https://doi. org/10.1016/j.carbpol.2010.08.051

44. Khalid S, Yu L, Meng L, Liu H, Ali A, Chen L (2017) Poly(lactic acid)/starch composites: effect of microstructure and morphology of starch granules on performance. J Appl Polym Sci 134:4550445516. https://doi.org/10.1002/app.45504

45. Baroroh U, Yusuf M, Rachman SD, Ishmayana S, Syamsunarno MRAA, Levita J (2017) The importance of surface-binding site towards starch-adsorptivity level in $\alpha$-amylase: a review on structural point of view. Enzyme Res 2017:1-11. https://doi. org/10.1155/2017/4086845

46. de Souza PM, de Oliveira Magalhães P (2010) Application of microbial $\alpha$-amylase in industry—a\&nbsp;review. Braz J Microbiol 41:850-861. https://doi.org/10.1590/S1517-8382201000 0400004

47. Bhat R, Karim A (2009) Impact of radiation processing on starch. Compr Rev Food Sci Food Saf 8:44-58. https://doi.org/10.111 1/j.1541-4337.2008.00066.x

48. Tsuji H, Hayashi T (2015) Hydrolytic degradation and crystallization behavior of linear 2-armed and star-shaped 4-armed poly(1lactide)s: effects of branching architecture and crystallinity. J Appl Polym Sci 132:41983-41996. https://doi.org/10.1002/app.41983

49. Dvorackova M, Svoboda P, Kostka L, Pekarova S (2015) Influence of biodegradation in thermophilic anaerobic aqueous conditions on crystallization of poly(butylene succinate). Polym Test 47:59-70. https://doi.org/10.1016/j.polymertesting.2015.08.006

50. Akcan N, Serin B, Uyar F (2012) Production and optimization parameters of amylases from Bacillus subtilis RSKK96 under solid state fermentation. Chem Biochem Eng Q 26:233-239

51. Ishii N, Inoue Y, Shimada K, Tezuka Y, Mitomo H, Kasuya K (2007) Fungal degradation of poly(ethylene succinate). Polym Degrad Stab 92:44-52. https://doi.org/10.1016/j.polymdegradstab .2006.09.014

Publisher's Note Springer Nature remains neutral with regard to jurisdictional claims in published maps and institutional affiliations. 